\title{
Effects of preoperative aspirin in coronary artery bypass grafting: A double-blind, placebo-controlled, randomized trial
}

\author{
Marek A. Deja, MD, PhD, ${ }^{\mathrm{a}}$ Tomasz Kargul, MD, ${ }^{\mathrm{a}}$ Wojciech Domaradzki, MD, ${ }^{\mathrm{a}}$ Tomasz Stącel, MD, ${ }^{\mathrm{a}}$ \\ Witold Mazur, MD, ${ }^{a}$ Wojciech Wojakowski, MD, PhD, ${ }^{\mathrm{b}}$ Radosław Gocoł, MD, ${ }^{\mathrm{a}}$ \\ Ewa Gaszewska-Żurek, MD, ${ }^{\mathrm{b}}$ Paweł Żurek, MD, ${ }^{\mathrm{a}}$ Agata Pytel, PharmD,${ }^{\mathrm{c}}$ and Stanisław Woś, MD, PhD ${ }^{\mathrm{a}}$
}

Objective: This trial was undertaken to determine the safety and efficacy of preoperative aspirin administration in a contemporary cardiac surgical practice setting.

\begin{abstract}
Methods: This randomized, double-blind, parallel-group, single-center trial involved patients with stable coronary artery disease who were assigned to receive either $300 \mathrm{mg}$ of aspirin or placebo the night before coronary bypass surgery. Using a random digit table, patients were allocated to receive the tablet from 1 of the 40 coded bottles containing either aspirin or placebo. Patients, surgeons, anesthetists, and investigators were all masked to treatment allocation. The primary safety end points were as follows: more than $750 \mathrm{~mL}$ of bleeding during the first postoperative 12 hours and more than $1000 \mathrm{~mL}$ of total discharge from the chest drains. The secondary efficacy end point was a composite of cardiovascular death, myocardial infarction, or repeat revascularization.
\end{abstract}

Results: A total of 390 patients were allocated to aspirin (387 analyzed) and 399 to placebo (396 analyzed). The follow-up median was 53 months. Fifty-four placebo recipients and 86 aspirin recipients bled more than $750 \mathrm{~mL}$ in the first 12 hours (odds ratio [OR], 1.81; 95\% confidence interval [CI], 1.25-2.63), while total chest drain discharge was above $1000 \mathrm{~mL}$ in 96 placebo and 131 aspirin recipients (OR, 1.60; 95\% CI, 1.17-2.18). Preoperative aspirin decreased the long-term hazard of nonfatal coronary event (infarction or repeat revascularization) - hazard ratio (HR), 0.58 (95\% CI, 0.33-0.99) — and tended to decrease the hazard of a major cardiac event (cardiovascular death, infarction, or repeat revascularization-HR, 0.65 [95\% CI, 0.41-1.03]).

Conclusions: Performing coronary grafts on aspirin is associated with increased postoperative bleeding but may decrease the long-term hazard of coronary events. (J Thorac Cardiovasc Surg 2012;144:204-9)

Supplemental material is available online.

The administration of aspirin shortly after coronary artery bypass grafting (CABG) has been shown to improve graft patency, reduce the number of ischemic events (myocardial infarction [MI] and stroke), and improve survival. ${ }^{1}$ To be effective in preventing graft occlusion, treatment must be started within 12 hours $^{2}$ or ideally even 6 hours $^{3}$ of CABG. Currently, many surgeons continue aspirin administration until surgery, ${ }^{4}$ despite current guidelines from The Society of Thoracic Surgeons ${ }^{5}$ and the American College of Cardiology/American Heart Association. ${ }^{6}$ These

From the Second Department of Cardiac Surgery, ${ }^{\mathrm{a}}$ the Third Department of Cardiology, ${ }^{\mathrm{b}}$ Medical University of Silesia, Katowice, Poland; and the Academic Pharmacy, ${ }^{\mathrm{c}}$ Katowice, Poland.

The study was conducted using statutory funds of Medical University of Silesia.

Disclosures: Authors have nothing to disclose with regard to commercial support.

Received for publication Nov 3, 2011; revisions received March 13, 2012; accepted

for publication April 3, 2012; available ahead of print May 3, 2012.

Address for reprints: Marek A. Deja, MD, PhD, Second Department of Cardiac Sur-

gery, Medical University of Silesia, Ul. Ziołowa 47, 40-635 Katowice, Poland

(E-mail: mdeja@sum.edu.pl).

$0022-5223 / \$ 36.00$

Copyright $(C) 2012$ by The American Association for Thoracic Surgery

doi:10.1016/j.jtcvs.2012.04.004 guidelines suggest that aspirin be discontinued in patients without acute coronary syndrome 3 and 7 days before surgery, respectively, and restarted within 6 hours and 48 hours after $\mathrm{CABG}$, respectively.

The practice of continuing aspirin until surgery is based on little evidence. The meta-analysis of 8 randomized trials including 805 patients and 14 observational studies (4485 patients) showed that preoperative aspirin increases postoperative bleeding, transfusion requirements, and chest reexploration for bleeding, while having no significant effect on MI or death. ${ }^{7}$ These studies were outdated and underpowered and the authors called for a new randomized trial of preoperative aspirin in the settings of contemporary cardiac surgical practice. ${ }^{7}$

The current trial was constructed to answer these questions.

\footnotetext{
METHODS

Study Design

We conducted a single-center, 1:1 randomized, double-blind, placebocontrolled trial to assess whether a single preoperative 300-mg dose of aspirin, 1 night before $\mathrm{CABG}$, is safe and effective. Patients subjected to their first-time elective $\mathrm{CABG}$, for whom aspirin was stopped 7 days before surgery, were eligible for the study. The exclusion criteria were as follows: age above 75 years, the need for concomitant cardiac procedure other than CABG, previous cardiac surgery, bleeding disorders, full blood count or
} 


$$
\begin{aligned}
& \text { Abbreviations and Acronyms } \\
& \begin{aligned}
\text { CABG } & =\text { coronary artery bypass grafting } \\
\text { CI } & =\text { confidence interval } \\
\text { CPB } & =\text { cardiopulmonary bypass } \\
\text { HR } & =\text { hazard ratio } \\
\text { MI } & =\text { myocardial infarction } \\
\text { OR } & =\text { odds ratio }
\end{aligned}
\end{aligned}
$$

from 1 of the bottles the night before surgery. The tablets were prepared and the bottles were coded by an independent pharmacist who was not involved in the patients' recruitment, sequence generation, or implementation. Patients, surgeons, anesthetists, nurses, and researchers were all blinded as to the content of the bottles.

The study was approved by the local bioethics committee and informed consent was obtained from all patients.

We used the Shapiro-Wilk test to confirm normal distribution of parametric data. Accordingly, the data were presented as means and standard deviations and were compared using the $t$ test, or as median with interquartile range and compared with the Mann-Whitney test. Patients' characteristics and outcomes were presented as percentages and compared using the $\chi^{2}$ test. To estimate the relative risk of the outcome in the aspirin group, we calculated the odds ratio (OR) with $95 \%$ confidence interval (CI). The parametric outcomes were presented either as a median with interquartile range or as a mean with $95 \% \mathrm{CI}$.

Cumulative event rates from the time of randomization were estimated using the Kaplan-Meier method and compared using the log-rank test. The hazard ratio (HR) with $95 \% \mathrm{CI}$ was derived from the Cox proportional hazards model. We used SPSS 14.0 for Windows (SPSS, Inc, Chicago, Ill) for statistical analysis.

\section{RESULTS \\ Study Population}

Between June 9, 2003, and July 1, 2006, we randomized 789 patients: 390 received aspirin and 399 placebo. Six patients were excluded from the analysis. The CONSORT flow diagram is presented in the online supplement (Figure E1). Five (1\%) patients were lost-to-follow-up after discharge. They were censored in all analyses on their discharge date. Another $74(10 \%)$ patients $(34[9 \%]$ in the aspirin and $40[10 \%]$ in the placebo group $[P=.6])$ were lost-to-follow-up at some later stage and censored in analyses on the day of last contact; however, their mortality data (with the cause of death) were brought up to date at database closure by checking with the national death register. The median duration of follow-up was 53.3 months (42.1-63.3 months).

Baseline demographic and clinical characteristics of patients are summarized in Table E1.

\section{Operative Procedure}

A median of 3 grafts per patient were constructed in both groups $(P=.8)$. There were no significant differences in the operative conduct between the groups. The details of the operation are summarized in Table 1.

\section{Safety Outcomes}

The chest drains were removed 30.8 hours $(27.7-32.2)$ and 31.2 hours (27.8-32.2) $(P=.4)$ after the operation in the placebo and aspirin groups, respectively. Fifty-four (14\%) patients receiving placebo and $86(22 \%)$ patients receiving aspirin bled more than $750 \mathrm{~mL}$ in the first 12 hours (OR, $1.81 ; 95 \%$ CI, $1.25-2.63 ; P=.002)$. Total chest drain discharge was more than $1000 \mathrm{~mL}$ in $96(24 \%)$ placebo and $131(34 \%)$ aspirin patients (OR, 1.60; 95\% CI, 1.17-2.18; $P=.003)$. The patients who received a single preoperative

\section{Randomization and Masking}

The 800 tablets containing either placebo or $300 \mathrm{mg}$ of aspirin were indiscernible and dispensed in 40 coded bottles, each containing 20 tablets. The patients were randomized by a random digit table to receive a tablet 
TABLE 1. Operative conduct

\begin{tabular}{lccc}
\hline & $\begin{array}{c}\text { Aspirin } \\
(\mathbf{n}=\mathbf{3 8 7})\end{array}$ & $\begin{array}{c}\text { Placebo } \\
(\mathbf{n}=\mathbf{3 9 6})\end{array}$ & $\boldsymbol{P}$ \\
\hline No. of distal anastomoses, median & $3(2-3)$ & $3(2-3)$ & .8 \\
$\quad$ Q1-Q3) & & & \\
LITA use, n (\%) & $382(99)$ & $392(99)$ & .8 \\
RITA use, n (\%) & $14(4)$ & $9(2)$ & .3 \\
RA use, n (\%) & $26(7)$ & $30(8)$ & .6 \\
Total arterial revascularization, & $51(13)$ & $58(15)$ & .6 \\
$\quad$ n (\%) & & & \\
Sequential grafts, n (\%) & $21(5)$ & $24(6)$ & .7 \\
Endarterectomy, n (\%) & $1(0)$ & $1(0)$ & .99 \\
OPCAB, n (\%) & $74(19)$ & $72(18)$ & .7 \\
On-pump: n (\%) & $313(81)$ & $324(82)$ & \\
CPB time (min), median & $62(50-76)$ & $64(50-76)$ & .8 \\
$\quad(Q 1-Q 3)$ & & & \\
AXC time (min), median & $35(28-44)$ & $36(29-44)$ & .4 \\
$\quad(Q 1-Q 3)$ & & & \\
Normothermia, n (\%) & & & \\
Miniplegia, n (\%) & & & \\
Prophylactic tranexamic acid, & $110(35)$ & $130(40)$ & .2 \\
$\quad$ n (\%) & & & .2 \\
Prophylactic aprotinin, n (\%) & $72(23)$ & $57(18)$ & .1 \\
Procedure time (min), median & $160(140-180)$ & $160(135-180)$ & .7 \\
$\quad$ (Q1-Q3) & & & \\
\hline
\end{tabular}
(Q1-Q3)

$\overline{Q 1-Q 3 \text {, Interquartile range; LITA, left internal thoracic artery; RITA, right internal }}$ thoracic artery; $R A$, radial artery; $O P C A B$, off-pump coronary artery bypass; $C P B$, cardiopulmonary bypass; $A X C$, aortic crossclamp.

300-mg dose of aspirin discharged $820 \mathrm{~mL}$ (630-1107) in total, and those who received the placebo discharged 750 $\mathrm{mL}(575-1000)(P=.006)$. The mean difference was estimated at $68 \mathrm{~mL}(95 \% \mathrm{CI}, 15-124 \mathrm{~mL}$ ) (Figure 1).

No difference in the need for chest reexploration was observed: $19(5 \%)$ versus $15(4 \%)(P=.4)$ in the aspirin and placebo groups, respectively (OR, $1.31 ; 95 \% \mathrm{CI}$, $0.66-2.62)$. Sixty patients in the placebo group (15\%) and

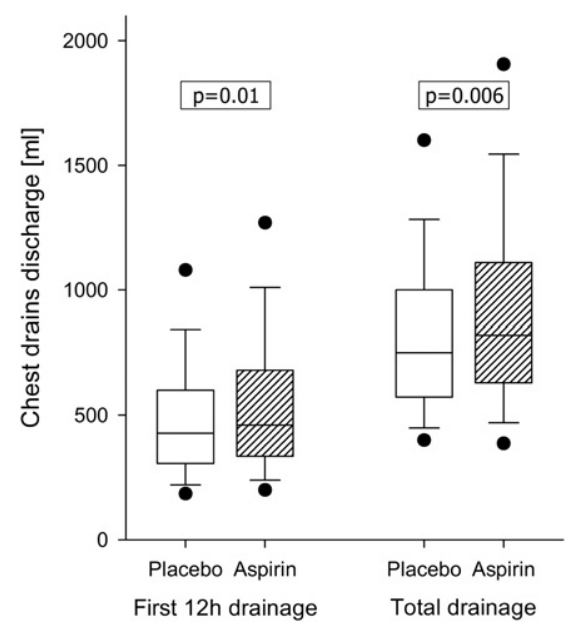

FIGURE 1. Chest drain discharge. Data are presented as median with interquartile range. Whiskers present 10th and 90th percentiles, and points present fifth and 95th percentiles.
TABLE 2. Blood product transfusions in postoperative period

\begin{tabular}{|c|c|c|c|}
\hline & $\begin{array}{c}\text { Aspirin } \\
(\mathbf{n}=\mathbf{3 8 7})\end{array}$ & $\begin{array}{l}\text { Placebo } \\
(\mathrm{n}=396)\end{array}$ & $\boldsymbol{P}$ \\
\hline \multicolumn{4}{|l|}{ Transfusion of PRBCs (units) } \\
\hline Mean $(95 \% \mathrm{CI})$ & $0.98(0.81-1.16)$ & $0.77(0.62-0.93)$ & \\
\hline Median & 0 & 0 & .06 \\
\hline Quartile 1-quartile 3 & $0-2$ & $0-1$ & \\
\hline Range & $0-14$ & $0-13$ & \\
\hline $\begin{array}{l}\text { Transfusion of PRBCs, no. } \\
\text { of patients ( } \%)\end{array}$ & $144(37)$ & $126(32)$ & .1 \\
\hline \multicolumn{4}{|l|}{ FFP transfusion (units) } \\
\hline Mean $(95 \% \mathrm{CI})$ & $0.76(0.60-0.92)$ & $0.46(0.34-0.58)$ & \\
\hline Median & 0 & 0 & .001 \\
\hline Quartile 1-quartile 3 & $0-1$ & $0-0$ & \\
\hline Range & $0-15$ & $0-11$ & \\
\hline $\begin{array}{l}\text { FFP transfusion, no. of } \\
\text { patients }(\%)\end{array}$ & $107(28)$ & $69(17)$ & .001 \\
\hline \multicolumn{4}{|l|}{ Platelet transfusion (units) } \\
\hline Mean $(95 \%$ CI $)$ & $0.06(0.03-0.10)$ & $0.02(0.01-0.04)$ & \\
\hline Median & 0 & 0 & .045 \\
\hline Quartile 1-quartile 3 & $0-0$ & $0-0$ & \\
\hline Range & $0-3$ & $0-1$ & \\
\hline $\begin{array}{l}\text { Platelet transfusion, no. } \\
\text { of patients }(\%)\end{array}$ & $18(5)$ & $9(2)$ & .07 \\
\hline
\end{tabular}

$86(22 \%)$ in the aspirin group experienced a hematocrit level below 25\% (OR, 1.60; 95\% CI, 1.11-2.30; $P=.01)$. We also observed some increase in blood product administration in the aspirin group (Table 2).

\section{Efficacy Outcomes}

We observed early major adverse cardiovascular event (death or MI or stroke within 30 days of surgery) in 12 $(3 \%)$ patients in the aspirin group and $19(5 \%)$ in the placebo group $(P=.2)$ (Table 3$)$. No differences in postoperative cardiac marker levels were observed (Figure E2).

Although we had no influence on long-term postoperative therapy, the data gathered on the last follow-up confirmed that they conformed to current guidelines and did not differ between the groups (Table E2).

A major cardiac event (cardiovascular death or MI or repeat revascularization, percutaneous in all cases) occurred in $30(8 \%)$ aspirin and $45(11 \%)$ placebo patients. The HR for preoperative aspirin was estimated at $0.65(95 \%$

TABLE 3. Early postoperative course

\begin{tabular}{lccl}
\hline & Aspirin $(\mathbf{n}=\mathbf{3 8 7})$ & Placebo $(\mathbf{n}=\mathbf{3 9 6})$ & $\boldsymbol{P}$ \\
\hline MACE (30 d), n (\%) & $12(3)$ & $19(5)$ & .2 \\
Death (30 d), n (\%) & $5(1)$ & $5(1)$ & .97 \\
Perioperative MI, n (\%) & $8(2)$ & $14(4)$ & .2 \\
Perioperative stroke, n (\%) & $2(1)$ & $3(1)$ & .7 \\
IABP, n (\%) & $13(3)$ & $23(6)$ & .1 \\
\hline
\end{tabular}

$M A C E$, Major adverse cardiovascular event (death or stroke or myocardial infarction); $M I$, myocardial infarction; IABP, intra-aortic balloon pump. 
CI, 0.41-1.03; $P=.06$ ) (Figure 2, $A)$. We observed $18(5 \%)$ deaths in the aspirin group and $22(6 \%)$ in the placebo group. Of those, 11 died of noncardiac causes: 1 in a car accident, 1 of pneumoconiosis, and 9 of neoplastic disease. Overall mortality and cardiovascular mortality did not differ between the groups, with HR for preoperative aspirin $0.83(95 \% \mathrm{CI}, 0.45-1.55 ; P=.5)$ and $0.62(95 \% \mathrm{CI}$, $0.29-1.31 ; P=.2$ ), respectively (Figure 2, $B$, Figure E3). We found that a nonfatal coronary event, defined as MI or repeat revascularization, was more likely to occur in the placebo group: HR for preoperative aspirin was $0.58(95 \% \mathrm{CI}$, $0.33-0.99 ; P=.046$ ) (Figure 2, $C$ ). The HR of MI was 0.59 (95\% CI, 0.30-1.18; $P=.1)$ and of repeat revascularization 0.66 (95\% CI, 0.31-1.43; $P=.3$ ).

\section{Subgroup Analysis}

No significant interaction of prespecified factors with study group assignment was observed in the cases of early outcomes (Figure E4).

Preoperative aspirin prevented long-term major cardiac events (cardiovascular death or MI or repeat revascularization) in patients operated on with CPB (HR, $0.54 ; 95 \%$ CI, $0.31-0.93 ; P=.03)$ and in patients receiving antifibrinolytic therapy (HR, $0.40 ; 95 \%$ CI, 0.17-0.97; $P=.04$ ); however, in neither case was the interaction with group assignment significant $(P=.2$ and $P=.3$, respectively) (Figure E5). The only significant interaction was the one between the influence of preoperative aspirin and the use of CPB in case of the hazard of long-term coronary event (MI or repeat revascularization $)(P=.02)$. This could suggest that the beneficial effect of aspirin may only be present in patients whose operation is performed on-pump (HR, 0.37; 95\% CI, $0.19-0.75 ; P=.005$ ) (Figure E5)

\section{DISCUSSION}

This study is, to our knowledge, the largest randomized trial of preoperative aspirin administration in cardiac surgery. It definitively shows that, in the settings of a contemporary cardiac surgical practice, preoperative aspirin administration increases the risk of postoperative bleeding. The results can be viewed in 2 ways. One may question the 70-mL average difference of total drain discharge as clinically unimportant (although statistically significant) and not resulting in an increased need for chest reexploration. On the other hand, the chance of bleeding in excess of 750 $\mathrm{mL}$ increased nearly twice, there was a $50 \%$ increase in the risk of the hematocrit value dropping below $25 \%$, and the risk of receiving more than 1 unit of packed red blood cells (not a prespecified end point) was significantly increased (OR, 1.45; 95\% CI, 1.04-2.02; $P=.03$ ). We believe the fact that some patients may have considerably increased postoperative bleeding owing to preoperative aspirin to be clinically more meaningful than the comfortingly small

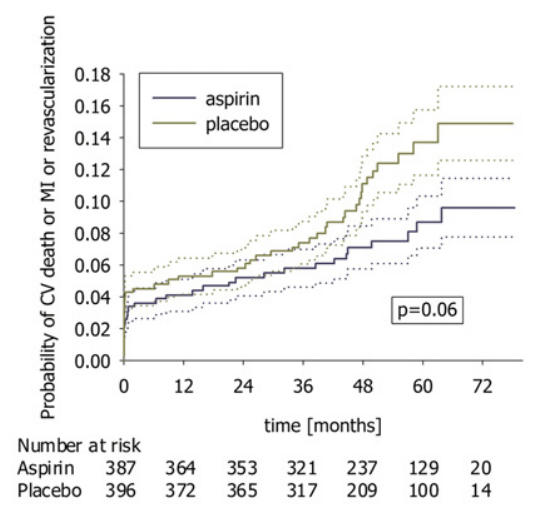

A
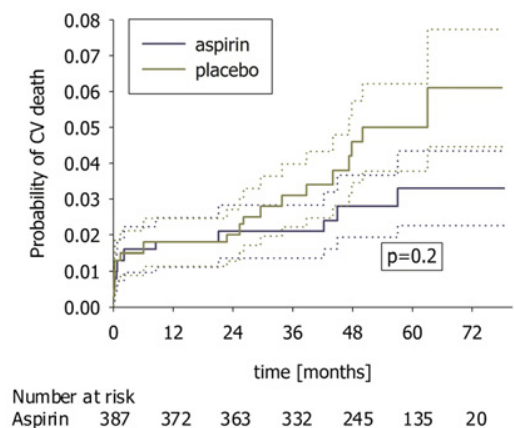

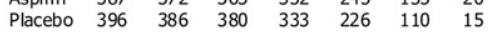

B

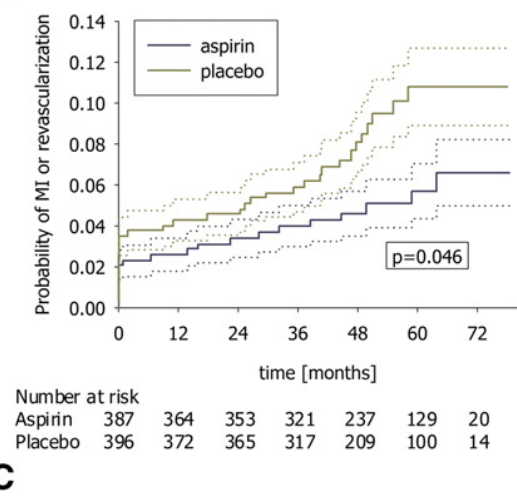

FIGURE 2. A, Probability of major cardiac event—cardiovascular $(C V)$ death, myocardial infarction $(M I)$, or repeat revascularization in the postoperative period. B, Probability of $\mathrm{CV}$ death in the postoperative period. $\mathrm{C}$, Probability of major nonfatal coronary event-MI or repeat revascularization in the postoperative period. Lines are the Kaplan-Meier estimates with standard error. $P$ is from log-rank comparison.

difference in median drainage. However, we acknowledge that some clinicians may argue the opposite.

Increased postoperative bleeding is not associated with any obvious decrease in early ischemic end points. Even the biomarker levels remained virtually the same in both groups. In view of the rather low incidence of early major adverse cardiovascular events, our study was underpowered for the detection of difference. Also, the fact that all patients received early postoperative aspirin might have mitigated the possible difference. ${ }^{1,2}$ Still, our results are in 
agreement with most other studies, ${ }^{7-13}$ including a recent retrospective report by Jacob and associates ${ }^{14}$ based on more than 4000 patients operated on at the Cleveland Clinic.

Two large retrospective studies ${ }^{15,16}$ showed no aspirin influence on postoperative chest drain discharge. The group assignment in both studies was based on whether or not patients received aspirin within the past 5 or 7 preoperative days, and true data on the proximity of aspirin therapy to $\mathrm{CABG}$, as well as aspirin dosage, are lacking in both articles. Meanwhile, aspirin therapy within 48 hours preoperatively may be crucial for the outcome. ${ }^{7,11}$

We decided to follow the patients up to detect end points that could be related to coronary events. Our study is the first, to our knowledge, to show some long-term benefit of preoperative aspirin administration. Preoperative aspirin tended to decrease the chance of a major cardiac event and decreased by $40 \%$ the long-term hazard of a coronary event developing (MI or repeated revascularization). However, these findings need to be treated with caution inasmuch as they are all secondary findings and result from analyses that were not initially planned.

It may appear strange that preoperative aspirin affects the long-term outcome without much effect on the early results of surgery, especially because it has primarily been shown to prevent mainly the early thrombotic occlusion and not the other types of graft disease. ${ }^{17}$ It may well be that subclinical, early closure of venous grafts could explain the need for revascularization and later MI coming to clinical attention. ${ }^{2,18}$ Obviously, this is just a speculation and would require angiographic data to be confirmed.

Platelet activation soon after surgery is much less pronounced in off-pump compared with on-pump CABG. ${ }^{19}$ This makes preoperative aspirin redundant for off-pump CABG, provided it is administered almost immediately postoperatively, and may explain why a statistically significant decrease in the incidence of major cardiac events is visible only in patients operated on with CPB.

\section{Limitations of the Study}

The obvious limitation of our study is that patients were receiving a single $300-\mathrm{mg}$ dose of aspirin before surgery, having stopped its use a week earlier. This is distinct from regularly administered aspirin right up until the operation, which would more accurately mimic the usual real-life course of events. We are aware of the viewpoint that continuing aspirin therapy until surgery may decrease the chance of acute coronary syndrome developing preoperatively. ${ }^{20}$ The design of our study does not allow for disproving such a possibility. This design was chosen, as it was the practice in our department to stop the aspirin a week before surgery in all patients, and patients were recruited into the study after being admitted for surgery. It made blinding easier and the groups pure from the methodologic point of view. Because nearly $90 \%$ of the antiplatelet effect of aspirin is obtained as early as 6 hours after administration of a single $\operatorname{dos}^{21}$ and is irreversible for the platelet lifetime, the result of our study can be easily extrapolated for continuous preoperative aspirin use.

We did not use a formal protocol regarding the chest reexploration and blood product transfusion, other than the criteria stated in the "Methods" section. In particular, we had no strict criteria regarding administration of the fresh frozen plasma and platelets. The decision was always made by the team on call, based on their clinical judgment including chest drainage, hematocrit level, international normalized ratio, and platelet level. We decided it was scientifically more appropriate to rely on the blinding and randomization, rather than create an artificial protocol not reflecting our everyday practice.

Another major limitation of the study is the inclusion of heterogeneous groups of patients, operated on with or without $\mathrm{CPB}$, as well as those receiving antifibrinolytic therapy. However, such a design of the study reflects the real life clinical practice in our setting. We tried to deal with these confounders by planning separate analyses of these prespecified subgroups. No significant interaction between the use of antifibrinolytics and treatment assignment was found. The result, suggesting that the benefit of preoperative aspirin administration might be limited to patients operated on on-pump, should be treated with extreme caution, coming from a subgroup analysis of a secondary outcome.

We excluded patients older than 75 years, who constitute a big part of contemporary practice. Similarly, we recruited only the patients with stable coronary artery disease, making the study less generalizable. It seems that the early efficacy outcomes might have differed more if the patients with acute coronary syndrome were included.

Furthermore, as stated earlier, the study was not primarily designed to examine the efficacy outcomes and therefore cannot give definite answers regarding the benefit of preoperative aspirin use. This would require a larger, multicenter randomized trial. Our study may help in designing such a trial and calculating the numbers needed to recruit. With a small number of end points, a trial aimed at definitively proving or disproving an early benefit of preoperative aspirin administration may require in excess of 4000 patients to achieve $80 \%$ power.

Finally, our study is somewhat dated. However, with the current practice of continuing aspirin right up to the operation, ${ }^{4}$ it may be even more difficult to organize such a trial nowadays.

\section{CONCLUSIONS}

Our data add to current knowledge regarding the risks and benefits of preoperative aspirin therapy. In the era when continuing aspirin up until the operation has become routine despite the lack of evidence to support this practice, our data suggest that some increase in postoperative 
bleeding, with an accompanying moderate rise in the transfusion rate, might be the price to pay for expected decrease of the hazard of nonfatal MI or repeat revascularization after $\mathrm{CABG}$.

We thank all the surgeons of the Second Department of Cardiac Surgery for agreeing to include their patients in the trial. We thank Professor Tadeusz Wilczok DSc PhD for his assistance with preparation of aspirin/placebo tablets. We appreciate the editorial help of Piers Murphy (Emmanuel College, University of Cambridge).

\section{References}

1. Mangano DT. Aspirin and mortality from coronary bypass surgery. $N$ Engl J Med. 2002;347:1309-17.

2. Goldman S, Copeland J, Moritz T, Henderson W, Zadina K, Ovitt T, et al. Saphenous vein graft patency 1 year after coronary artery bypass surgery and effects of antiplatelet therapy. Results of a Veterans Administration Cooperative Study. Circulation. 1989;80:1190-7.

3. Goldman S, Copeland J, Moritz T, Henderson W, Zadina K, Ovitt T, et al. Starting aspirin therapy after operation. Effects on early graft patency. Department of Veterans Affairs Cooperative Study Group. Circulation. 1991;84:520-6.

4. ElBardissi AW, Aranki SF, Sheng S, O'Brien SM, Greenberg CC, Gammie JS. Trends in isolated coronary artery bypass grafting: an analysis of the Society of Thoracic Surgeons adult cardiac surgery database. J Thorac Cardiovasc Surg. 2012;143:273-81.

5. Ferraris VA, Ferraris SP, Moliterno DJ, Camp P, Walenga JM, Messmore HL, et al. The Society of Thoracic Surgeons practice guideline series: aspirin and other antiplatelet agents during operative coronary revascularization (executive summary). Ann Thorac Surg. 2005;79:1454-61.

6. Eagle KA, Guyton RA, Davidoff R, Edwards FH, Ewy GA, Gardner TJ, et al. ACC/AHA 2004 guideline update for coronary artery bypass graft surgery: summary article. A report of the American College of Cardiology/American Heart Association Task Force on Practice Guidelines (Committee to Update the 1999 Guidelines for Coronary Artery Bypass Graft Surgery). J Am Coll Cardiol. 2004;44:e213-310

7. Sun JC, Whitlock R, Cheng J, Eikelboom JW, Thabane L, Crowther MA, et al. The effect of pre-operative aspirin on bleeding, transfusion, myocardial infarction, and mortality in coronary artery bypass surgery: a systematic review of randomized and observational studies. Eur Heart J. 2008;29:1057-71.

8. Ferraris VA, Ferraris SP, Lough FC, Berry WR. Preoperative aspirin ingestion increases operative blood loss after coronary artery bypass grafting. Ann Thorac Surg. 1988;45:71-4.
9. Morawski W, Sanak M, Cisowski M, Szczeklik M, Szczeklik W, Dropinski J, et al. Prediction of the excessive perioperative bleeding in patients undergoing coronary artery bypass grafting: role of aspirin and platelet glycoprotein IIIa polymorphism. J Thorac Cardiovasc Surg. 2005;130:791-6.

10. Rawitscher RE, Jones JW, McCoy TA, Lindsley DA. A prospective study of aspirin's effect on red blood cell loss in cardiac surgery. J Cardiovasc Surg (Torino). 1991;32:1-7.

11. Weightman WM, Gibbs NM, Weidmann CR, Newman MA, Grey DE Sheminant MR, et al. The effect of preoperative aspirin-free interval on red blood cell transfusion requirements in cardiac surgical patients. $J$ Cardiothorac Vasc Anesth. 2002;16:54-8.

12. Kallis P, Tooze JA, Talbot S, Cowans D, Bevan DH, Treasure T. Pre-operative aspirin decreases platelet aggregation and increases post-operative blood loss - a prospective, randomised, placebo controlled, double-blind clinical trial in 100 patients with chronic stable angina. Eur J Cardiothorac Surg. 1994;8: 404-9.

13. Michelson EL, Morganroth J, Torosian M, Mac VH III. Relation of preoperative use of aspirin to increased mediastinal blood loss after coronary artery bypass graft surgery. J Thorac Cardiovasc Surg. 1978;76:694-7.

14. Jacob M, Smedira N, Blackstone E, Williams S, Cho L. Effect of timing of chronic preoperative aspirin discontinuation on morbidity and mortality in coronary artery bypass surgery. Circulation. 2011;123:577-83.

15. Dacey LJ, Munoz JJ, Johnson ER, Leavitt BJ, Maloney CT, Morton JR, et al. Effect of preoperative aspirin use on mortality in coronary artery bypass grafting patients. Ann Thorac Surg. 2000;70:1986-90.

16. Bybee KA, Powell BD, Valeti U, Rosales AG, Kopecky SL, Mullany C, et al. Preoperative aspirin therapy is associated with improved postoperative outcomes in patients undergoing coronary artery bypass grafting. Circulation. 2005;112(9 Suppl):I286-92.

17. Fuster V, Chesebro JH. Role of platelets and platelet inhibitors in aortocoronary artery vein-graft disease. Circulation. 1986;73:227-32.

18. FitzGibbon GM, Kafka HP, Leach AJ, Keon WJ, Hooper GD, Burton JR. Coronary bypass graft fate and patient outcome: angiographic follow-up of 5,065 grafts related to survival and reoperation in 1,388 patients during 25 years. J Am Coll Cardiol. 1996;28:616-26.

19. Ballotta A, Saleh HZ, El Baghdady HW, Gomaa M, Belloli F, Kandil H, et al Comparison of early platelet activation in patients undergoing on-pump versus off-pump coronary artery bypass surgery. J Thorac Cardiovasc Surg. 2007; 134:132-8.

20. Burger W, Chemnitius JM, Kneissl GD, Rucker G. Low-dose aspirin for secondary cardiovascular prevention—cardiovascular risks after its perioperative withdrawal versus bleeding risks with its continuation-review and meta-analysis J Intern Med. 2005;257:399-414.

21. Burch JW, Stanford N, Majerus PW. Inhibition of platelet prostaglandin synthetase by oral aspirin. J Clin Invest. 1978;61:314-9. 


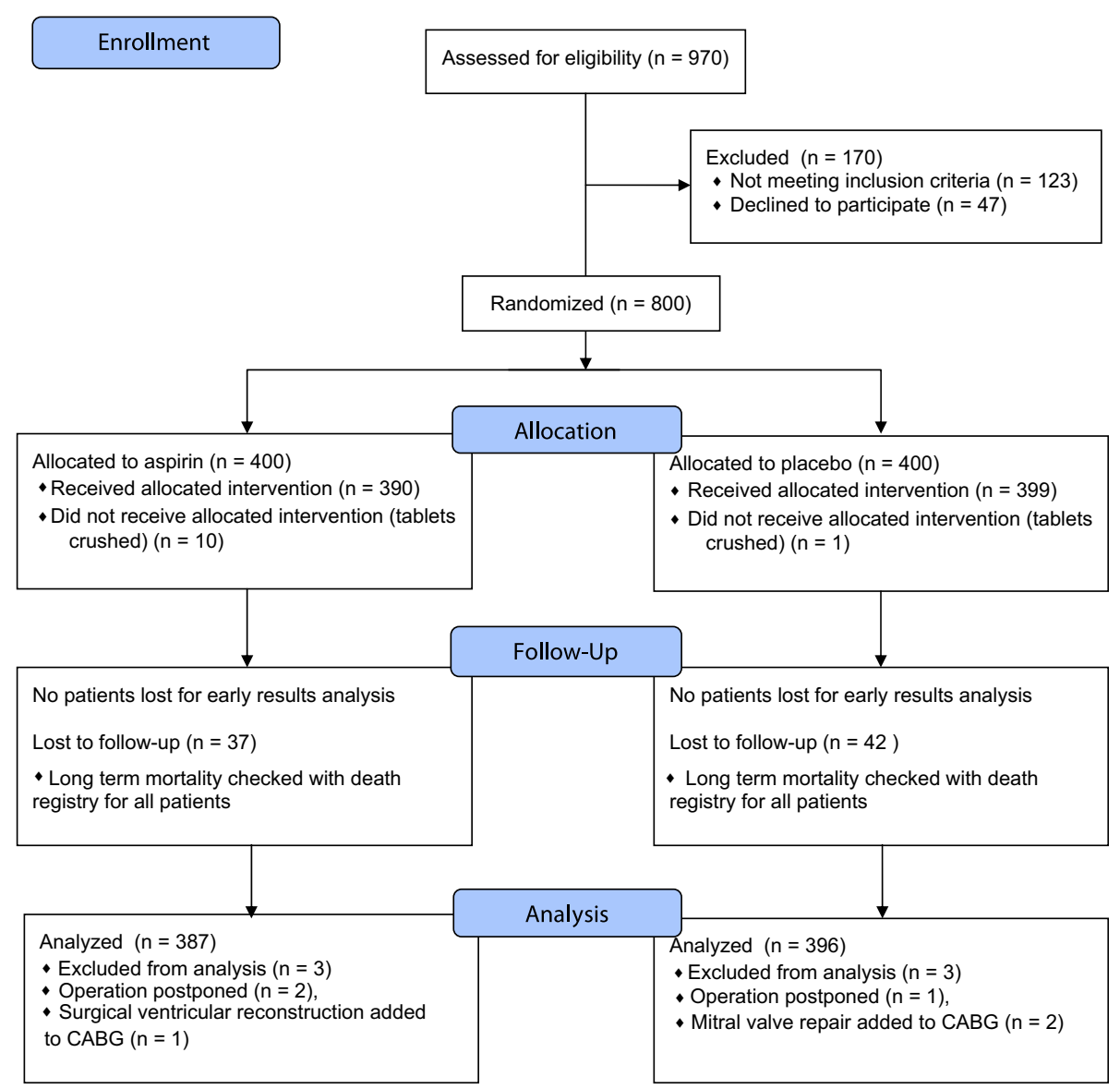

FIGURE E1. CONSORT flow diagram. $C A B G$, Coronary artery bypass grafting.
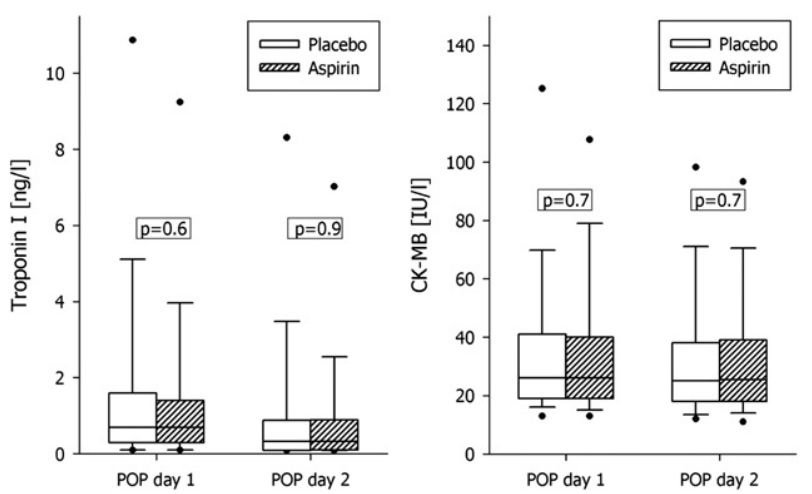

FIGURE E2. Cardiac markers levels in postoperative period. Data are presented as median with interquartile range. Whiskers present 10th and 90th percentile; points present fifth and 95th percentiles. $C K-M B$, Creatine kinase-myocardial band; $P O P$ day, day after surgery.

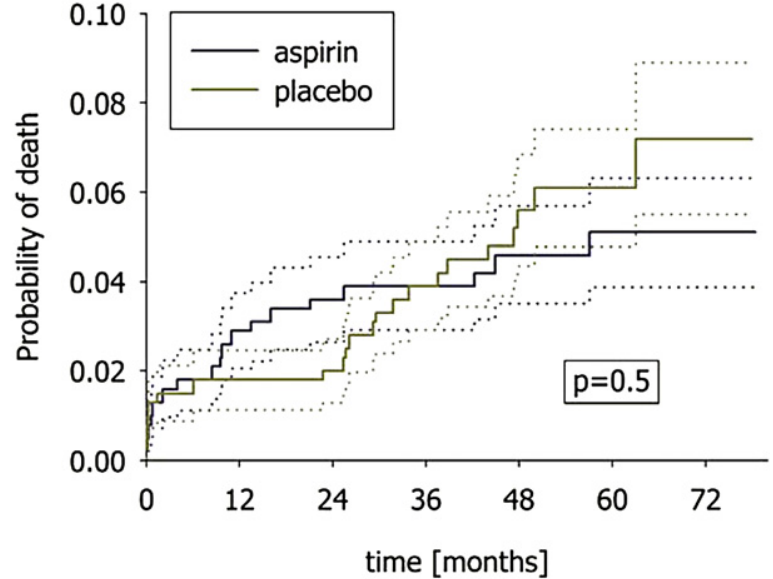

Number at risk

$\begin{array}{llllllll}\text { Aspirin } & 387 & 372 & 363 & 332 & 245 & 135 & 20 \\ \text { Placebo } & 396 & 386 & 380 & 333 & 226 & 110 & 15\end{array}$

FIGURE E3. Probability of death in postoperative period. Lines are the Kaplan-Meier estimates with standard error. $P$ is from the log-rank comparison. 


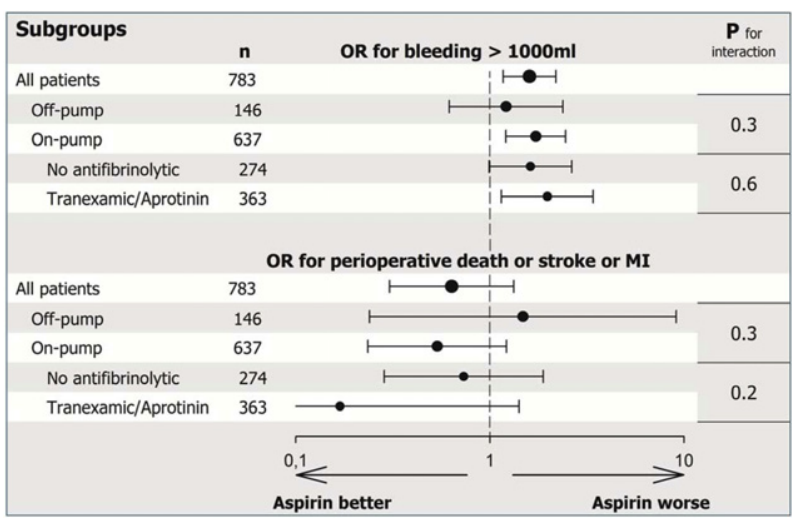

FIGURE E4. The influence of preoperative aspirin administration on early end points in prespecified subgroups. Data are presented as odds ratio $(O R)$ with $95 \%$ confidence interval. $P$ value for interaction between the factor and the treatment assignment is given. MI, Myocardial infarction.

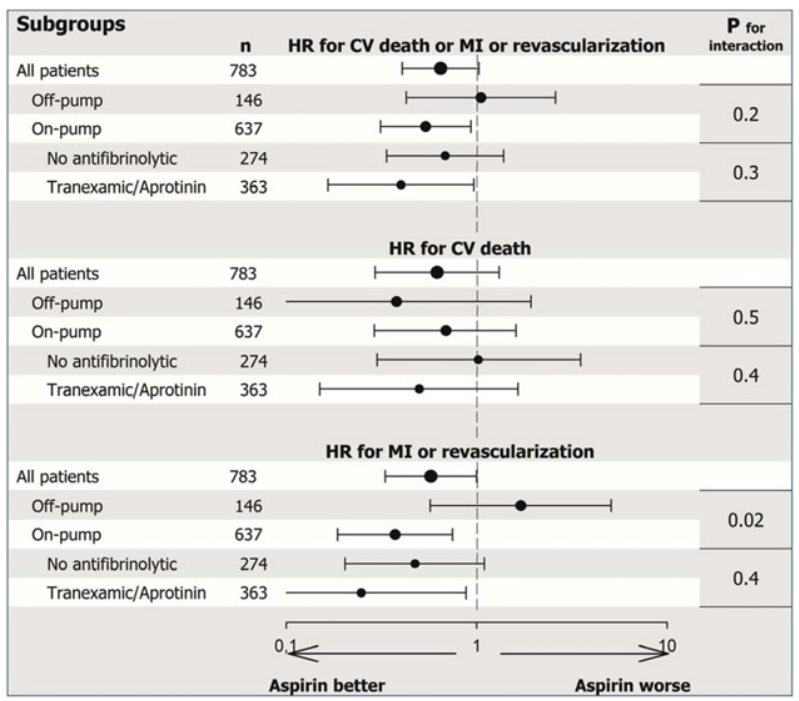

FIGURE E5. The influence of preoperative aspirin administration on long-term end points in prespecified subgroups. Data are presented as hazard ratio $(H R)$ with $95 \%$ confidence interval. $P$ value for interaction between the factor and the treatment assignment is given. $C V$, Cardiovascular; $M I$, myocardial infarction.
TABLE E1. Patient characteristics

\begin{tabular}{|c|c|c|}
\hline & $\begin{array}{c}\text { Aspirin } \\
(\mathbf{n}=\mathbf{3 8 7})\end{array}$ & $\begin{array}{c}\text { Placebo } \\
(n=396)\end{array}$ \\
\hline Age (y), median (Q1-Q3) & $59(53-66)$ & $59(54-66)$ \\
\hline BMI, median (Q1-Q3) & $28(26-30)$ & $28(25-30)$ \\
\hline Sex (male), n $(\%)$ & $315(81)$ & $297(75)$ \\
\hline \multicolumn{3}{|l|}{ CCS class } \\
\hline $\mathrm{I}, \mathrm{n}(\%)$ & $43(11)$ & $48(12)$ \\
\hline II, n (\%) & $177(46)$ & $162(41)$ \\
\hline III, n (\%) & $162(42)$ & $169(43)$ \\
\hline $\mathrm{IV}, \mathrm{n}(\%)$ & $5(1)$ & $17(4)$ \\
\hline \multicolumn{3}{|l|}{ NYHA class } \\
\hline I, n (\%) & $182(47)$ & $189(48)$ \\
\hline II, n $(\%)$ & $190(49)$ & $193(49)$ \\
\hline III, n $(\%)$ & $15(4)$ & $14(4)$ \\
\hline \multicolumn{3}{|l|}{ Previous MI } \\
\hline $0, \mathrm{n}(\%)$ & $118(30)$ & $119(30)$ \\
\hline $1, \mathrm{n}(\%)$ & $230(59)$ & $245(62)$ \\
\hline$>1, \mathrm{n}(\%)$ & $39(10)$ & $32(8)$ \\
\hline Previous PCI, n (\%) & $93(24)$ & $98(25)$ \\
\hline $\begin{array}{l}\text { Time from PCI }(\mathrm{m}), \text { median } \\
\text { (Q1-Q3) }\end{array}$ & $4(2-7)$ & $4(2-10)$ \\
\hline \multicolumn{3}{|l|}{ Coronary vessels affected } \\
\hline One-vessel disease, n (\%) & $12(3)$ & $20(5)$ \\
\hline Two-vessel disease, $\mathrm{n}(\%)$ & $68(18)$ & $65(16)$ \\
\hline Three-vessel disease, $\mathrm{n}(\%)$ & $274(71)$ & $272(69)$ \\
\hline LM disease, $\mathrm{n}(\%)$ & $33(9)$ & $39(10)$ \\
\hline \multicolumn{3}{|l|}{ LV function } \\
\hline Poor $(\mathrm{EF}<30 \%), \mathrm{n}(\%)$ & $10(3)$ & $4(1)$ \\
\hline Moderate (EF 30\%-50\%), n (\%) & $140(36)$ & $150(38)$ \\
\hline Good $(\mathrm{EF}>50 \%), \mathrm{n}(\%)$ & $237(61)$ & $242(61)$ \\
\hline Mild MR, n (\%) & $99(26)$ & $96(24)$ \\
\hline History of AF, n (\%) & $17(4)$ & $23(6)$ \\
\hline $\mathrm{COPD}, \mathrm{n}(\%)$ & $15(4)$ & $26(7)$ \\
\hline Diabetes mellitus, n (\%) & $105(27)$ & $94(25)$ \\
\hline Hypertension, n (\%) & $331(86)$ & $320(81)$ \\
\hline Hyperlipidemia, n (\%) & $343(89)$ & $340(86)$ \\
\hline History of CVA, n (\%) & $31(8)$ & $23(6)$ \\
\hline PVD, n (\%) & $44(11)$ & $36(9)$ \\
\hline \multicolumn{3}{|l|}{ History of smoking } \\
\hline Past smoker, n (\%) & $256(66)$ & $251(63)$ \\
\hline Active smoker, n (\%) & $36(9)$ & $45(11)$ \\
\hline Nonsmoker, n (\%) & $95(25)$ & $100(25)$ \\
\hline \multicolumn{3}{|l|}{ Full blood count } \\
\hline WBC $\left(10^{9} / \mathrm{L}\right)$, median (Q1-Q3) & $7.0(6.0-8.4)$ & $7.0(6.0-8.2)$ \\
\hline $\mathrm{RBC}\left(10^{12} / \mathrm{L}\right)$, median $(\mathrm{Q} 1-\mathrm{Q} 3)$ & $4.6(4.4-4.9)$ & $4.6(4.3-4.8)$ \\
\hline $\mathrm{Hb}(\mathrm{g} / \mathrm{dL})$, median (Q1-Q3) & $14.5(13.9-15.2)$ & $14.3(13.6-15.0)$ \\
\hline Hct (\%), median (Q1-Q3) & $42(40-44)$ & $41(40-43)$ \\
\hline Plt $\left(10^{9} / \mathrm{L}\right)$, median $(\mathrm{Q} 1-\mathrm{Q} 3)$ & $195(166-226)$ & $195(168-224)$ \\
\hline Creatinine $(\mu \mathrm{mol} / \mathrm{L})$, median $(\mathrm{Q} 1-\mathrm{Q} 3)$ & $88(79-106)$ & $88(79-97)$ \\
\hline
\end{tabular}

eGRF (mL/min per $\left.1.73 \mathrm{~m}^{2}\right)$, median 73.9 (64.4-84.2) $74.8(64.7-84.3)$ (Q1-Q3)

Q1-Q3, Interquartile range; $B M I$, body mass index; $C C S$, Canadian Cardiovascular Society; NYHA, New York Heart Association; $M I$, myocardial infarction; $P C I$, percutaneous coronary intervention; $L M$, left main coronary artery; $L V$, left ventricle; $E F$ ejection fraction; $M R$, mitral regurgitation; $A F$, atrial fibrillation; $C O P D$, chronic obstructive pulmonary disease; $C V A$, cerebral vascular accident; $P V D$, peripheral vascular disease; $W B C$, white blood cells; $R B C$, red blood cells; $H b$, hemoglobin; Hct, hematocrit; Plt, platelets; $e G R F$, estimated glomerular filtration rate. 
TABLE E2. Therapy on last contact

\begin{tabular}{lccc}
\hline & Aspirin $(\mathbf{n}=\mathbf{3 3 0})$ & Placebo $(\mathbf{n}=\mathbf{3 3 9})$ & $\boldsymbol{P}$ \\
\hline ACE inhibitors, n (\%) & $251(76)$ & $244(72)$ & .2 \\
Aspirin, n (\%) & $315(96)$ & $330(97)$ & .2 \\
Beta-blockers, n (\%) & $310(94)$ & $311(92)$ & .3 \\
Nitrates, n (\%) & $39(12)$ & $39(12)$ & .9 \\
Insulin, n (\%) & $8(2)$ & $10(3)$ & .7 \\
Statins, n (\%) & $312(95)$ & $315(93)$ & .4 \\
\hline
\end{tabular}

$A C E$, Angiotensin-converting enzyme. 